\title{
Health impact assessment of housing improvements: incorporating research evidence
}

\author{
H Thomson, M Petticrew, M Douglas
}

J Epidemiol Community Health 2003;57:1 1-16

See end of article for authors' affiliations

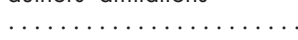

Correspondence to: Ms H Thomson, MRC Social and Public Health Sciences Unit, 4 Lilybank Gardens, Glasgow G12 8RZ, UK:

hilary@msoc.mrc.gla.ac.uk

Accepted for publication 2 May 2002

\begin{abstract}
Background: Health impact assessment (HIA) has been widely recommended for future social policies and investment, such as housing improvement. However, concerns have been raised about the utility and predictive value of an HIA. Use of existing research data would add more weight to forecasts by an HIA.

Methods, results, and conclusions: A recent systematic review of housing intervention studies found a lack of research. The authors recommended that a broader evidence base would be needed to support HIA. In response to consultation with policymakers and HIA practitioners this paper presents a way in which research can be used to inform HIA. Based on the systematic review, the authors have developed a table of synthesised findings indicating the expected health effects of specific housing improvements. The authors also reviewed observational data of housing associated health risks to highlight the key impacts to consider when doing a housing HIA. The findings are presented and the authors discuss how they should be used to inform evidence based housing HIA. In addition to considering the existing research, HIA must consider the local relevance of research. Consultation with local stakeholders also needs to be incorporated to the final assessment. The lack of data and the difficulties in gathering and reviewing data mean that not all HIAs will be able to be informed by research evidence. Well conducted prospective validation of HIAs would contribute to the development of healthy housing investment by informing future housing HIA.
\end{abstract}

$\mathrm{H}$ ealth impact assessment (HIA) has been recommended for all new policies. ${ }^{1}$ However, HIAs have been criticised for being subjective and failing to account for their use of evidence. ${ }^{2}$ Toolkits and guidelines on HIA have been produced but proposals to develop an evidence base for topic specific HIAs have not yet been realised. ${ }^{3}$ It is important that a serious attempt is made to locate and provide what evidence is available and to present it in such a format as to maximise its potential for influence.

Research evidence of specific policies or interventions can be gathered and systematically reviewed to produce accessible summaries that can assist those carrying out HIAs in specific areas. We recently carried out a systematic review of the health effects of housing improvements. ${ }^{4}$ This review included retrospective, prospective, controlled, and uncontrolled studies from all over the world in any language. Despite broad inclusion criteria the lack of studies, the range of interventions and outcomes used, and the low study quality made synthesising the findings difficult. We concluded that there was a lack of research evidence from intervention studies alone to support improved housing as a means to improve health and that other sources of evidence should be used in addition to help inform current housing HIAs.

In response to consultation with policy makers and HIA practitioners this paper presents the findings of the systematic review highlighting the type of outcomes observed after specific housing improvement (table 1). In addition to the systematic review we have incorporated a broader evidence base of observational research, to produce evidence informed guidance on what health effects to expect and what questions to ask for those carrying out housing HIAs (boxes 2 and 3). This paper tackles the issue of presenting research evidence in a way that can inform prospective HIAs of housing improvement projects or policies.

\section{Scope of the review}

The literature reviewed here relates to housing conditions and does not specifically include furniture interventions or interventions to reduce home accidents, falls, or fires or impacts of area regeneration. Four systematic reviews covering these topics and a comprehensive review on homelessness were identified but are outwith the scope of this paper. ${ }^{5-10}$ Literature on radon, lead, and carbon monoxide were also excluded as there are already measures in place to protect residents from those hazards.

\section{EXISTING EVIDENCE OF HEALTH AND SOCIAL EFFECTS OF HOUSING IMPROVEMENTS}

Table 1 shows the main effects of different types of housing improvements on six main broad health and social outcomes. The findings are a synthesis of the data from the intervention studies reviewed and we indicate the strength of evidence for each finding.

\section{General physical health and illness episodes}

Thirteen studies assessed changes in general health after housing improvement. ${ }^{11-25}$ Measures used included self reported wellbeing, activity, symptoms or illness episodes, and health service use. Two studies used a validated general health measurement. ${ }^{2026}$ Ten studies found some health improvements ${ }^{11} 13-17192022-25$ and five studies found no difference in some measures. Some studies found mixed effects. $^{12} 1520$

Three studies of rehousing and community regeneration reported adverse effects on general health. ${ }^{12}{ }^{15} 27$ One study found increases in reported illness episodes $(+56 \%),{ }^{15}$ though this was in part attributed to a flu epidemic. In a further study, age standardised mortality rates increased for all ages, except infants, five years after rehousing from a slum area. ${ }^{27}$

\section{Mental health}

Half the studies identified used a measure of mental wellbeing (including the Hospital Anxiety and Depression Scale (HADs), self reported mental health and hypnotic prescribing levels). ${ }^{12-15} 172022232628-30$ These studies assessed the health 
Table 1 Evidence from controlled and uncontrolled intervention studies of specific health impacts of housing

\begin{tabular}{|c|c|c|c|c|c|c|c|c|c|}
\hline $\begin{array}{l}\text { Impact on } \\
\text { outcomes } \\
\text { measured }\end{array}$ & $\begin{array}{l}\text { General health or } \\
\text { wellbeing }\end{array}$ & $\begin{array}{l}\text { Symptoms/illness } \\
\text { and health service } \\
\text { use }\end{array}$ & \multicolumn{2}{|c|}{ Respiratory } & \multicolumn{2}{|c|}{ Mental health } & Mortality & \multicolumn{2}{|c|}{ Social } \\
\hline \multicolumn{10}{|c|}{ Rehousing/refurbishment plus relocation from slum area or community regeneration } \\
\hline & $\begin{aligned} & \Leftrightarrow \text { Unclear impact } \\
& \text { on measures of } \\
& \text { general health + }\end{aligned}$ & $\begin{array}{l}\Leftrightarrow \text { Unclear impact } \\
\text { on symptoms or } \\
\text { illness episodes } \\
++\end{array}$ & $\Leftrightarrow$ & $\begin{array}{l}\text { Conflicting } \\
\text { findings from } \\
\text { four studies }\end{array}$ & $\Uparrow$ & $\begin{array}{l}\text { Consistent } \\
\text { improvements in } \\
\text { mental health ++ }\end{array}$ & $\Downarrow \quad$ Increased + & $\Uparrow$ & $\begin{array}{l}\text { Numbers of smokers } \\
\text { reduced + }\end{array}$ \\
\hline & & $\begin{aligned} & \Leftrightarrow \text { Unclear effects } \\
& \text { on health service } \\
& \text { use }+\end{aligned}$ & & & & & & $\Downarrow$ & $\begin{array}{l}\text { Increased community } \\
\text { involvement, social } \\
\text { support, sense of } \\
\text { belonging and feeling of } \\
\text { safety. Reduced fear of } \\
\text { crime and sense of } \\
\text { isolation + } \\
\text { Increased rents led to } \\
\text { reduced income to buy } \\
\text { adequate diet + }\end{array}$ \\
\hline \multicolumn{10}{|c|}{ Medical priority rehousing (MPR) } \\
\hline $5-$ & 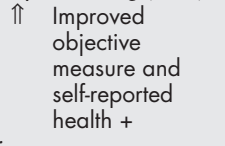 & $\begin{aligned} & \Leftrightarrow \text { Unclear impact } \\
& \text { on health service } \\
& \text { use }+\end{aligned}$ & & & $\Uparrow$ & $\begin{array}{l}\text { Improvement in } \\
\text { objective } \\
\text { measure and } \\
\text { self-reported } \\
\text { mental health ++ }\end{array}$ & & & \\
\hline \multicolumn{10}{|c|}{ Energy efficiency measures } \\
\hline & $\begin{array}{l}\Uparrow \quad \begin{array}{l}\text { Improved } \\
\text { objective } \\
\text { measure of } \\
\text { health }+\end{array}\end{array}$ & $\Leftrightarrow \begin{array}{l}\text { Unclear impact } \\
\text { on general } \\
\text { symptoms + }\end{array}$ & $\Uparrow$ & $\begin{array}{l}\text { Reduction in } \\
\text { respiratory } \\
\text { symptoms + }\end{array}$ & $\Leftrightarrow$ & $\begin{array}{l}\text { No significant } \\
\text { difference in } \\
\text { emotion and } \\
\text { mental health + }\end{array}$ & & $\Uparrow$ & $\begin{array}{l}\text { Less school time lost due to } \\
\text { asthma, but not other } \\
\text { symptoms + }\end{array}$ \\
\hline
\end{tabular}

Direction of effect: $\Uparrow$ improvements to health or reductions in illness; $\Leftrightarrow$ no clear effect on health or illness indicators; $\Downarrow$ reductions in health or increases in illness. Strength of evidence: +++ strong association: evidence from prospective controlled studies with good levels of follow up; ++ moderate association: evidence from at least one prospective controlled studies; + weak association: evidence from uncontrolled studies.

impacts of Medical Priority rehousing, energy efficiency improvements, refurbishment, rehousing, and area regeneration. All of these studies, except one study of central heating installation, ${ }^{17}{ }^{26}$ found improvements one month to five years after the housing improvements were completed. In one large, prospective controlled study the degree of improvement in mental health was directly related to the extent of housing improvement, demonstrating a dose-response relation. ${ }^{23}$ This consistent pattern of improvements in mental health would suggest that improving housing would generate mental health gains.

\section{Respiratory health}

Four studies looked at changes in respiratory symptoms. ${ }^{12} 152128$ Measures used included self reported symptoms and respiratory prescribing. Three of these studies were of rehousing and area regeneration; two of the studies reported increases in respiratory symptoms. One study found an increase in chronic respiratory conditions $(+12 \%)$ among adults five years after the move ${ }^{12}$ while the other study found reductions $(-11 \%)$ in bronchial and asthmatic symptoms one to four years after the move. ${ }^{15}$ The study of routine respiratory prescribing data found no significant changes, though the use of routine data that are not linked to individuals is not easy to interpret.

In the fourth study, children's respiratory symptoms improved and fewer days were lost from school because of asthma three months after installation of central heating. ${ }^{21}$

\section{OTHER EFFECTS OF HOUSING IMPROVEMENTS \\ Social context}

Four studies measured changes in a range of social outcomes and each found improvements after the housing improvement. Residents reported a reduced sense of isolation, reduced fear of crime, increased sense of belonging and feelings of safety, increased involvement in community affairs, greater recognition of neighbours, and improved view of the area as a place to live..$^{152430}$ These are important changes and may effect residents satisfaction with their house, however, it is not known if improvements in such measures translate into health improvements.

\section{Increased rents}

Two studies of rehousing and area regeneration provide good examples of the potential for unintended adverse effects because of increased rents. One study reported increases in standardised mortality rates in the rehoused residents. This was attributed to a doubling in rents, which in turn affected the households' ability to buy an adequate diet. ${ }^{27}$ More recent work in Stepney also reported that rents in the new houses increased by an average of $14.8 \%$, and some residents reported this as a barrier to employment opportunities. Some residents reported economising on food to accommodate the increase in rent. ${ }^{15}$

Using other sources of evidence on housing and health The strongest research evidence of health gains generated by housing investment is most likely to come from completed intervention studies. However in the absence of this, it is necessary to consider other data sources. The following sections provide a selective review of observational and qualitative literature that has linked poor housing conditions to health. Where available up to date systematic reviews or comprehensive expert reviews were used to inform this review.

\section{OBSERVATIONAL EVIDENCE IN HOUSING}

There are many housing characteristics that have been strongly associated with poor health using observational data. A comprehensive, expert review of the associated risks and health hazards in domestic buildings identified hygrothermal conditions, radon, falls, house dust mites, environmental tobacco smoke, and fires as the highest health risks. ${ }^{31}$ The main housing factors associated with health variation and that are commonly part of or aspects associated with housing improvements are listed in box 1; these should be considered in an HIA of housing improvements. 
Box 1 Main housing factors that have been associated with health variation and targeted as part of common housing improvements

- Indoor air quality

- House dust mite and allergens

- Dampness and hygrothermal conditions

- Temperature and warmth

- Home ownership

- House type and design, for example, flat or house

Other issues associated with housing improvement

- Moving and relocation

- Displacement

- Area effects

- Housing costs

\section{Indoor air quality}

In a recent expert review of the health effects of exposure to airborne particles in the home, the findings of observational, human, epidemiological, and toxicological animal studies were reviewed. The most common airborne particles arise from environmental tobacco smoke, cooking, certain heating appliances, and human activity. The level of indoor particles is strongly correlated with outdoor levels and raises personal exposure substantially. Short-term increases in ambient particles are strongly associated with increased mortality and morbidity; acute cardiopulmonary impairment being the predominant impact and vulnerable groups such as the elderly people and people with asthma being most at risk. ${ }^{32}$

\section{Dampness and hygrothermal conditions}

No recent systematic reviews of associations between dampness, mould, and health have been identified. In a review of studies of the associations between damp and mould and respiratory health the authors concluded that if the home was damp or mouldy the increased risk of respiratory symptoms was small, and recommended that new build housing is designed to prevent the proliferation of indoor allergens. ${ }^{33}$

\section{Allergens}

The most important allergen in house dust comes from the house dust mite. A systematic review ${ }^{9}$ of the effectiveness of house dust mite control measures in the management of asthma has been carried out. Measures used included vacuuming and acaricidal chemical measures. The authors concluded that current chemical and physical measures to reduce exposure to house dust mite allergens seem to be ineffective in the management of asthma. This is partly because asthma sufferers are often sensitive to other allergens as well as house dust mite.

\section{Temperature and warmth}

There is considerable seasonal variation in mortality in the UK that is strongly related to reductions in outdoor temperatures. $^{34}$ Recent analyses suggest that the seasonal variations are related to indoor rather than outdoor temperature, and that this annual variation could be reduced by helping residents protect themselves from cold weather conditions. ${ }^{35-37}$

\section{Housing tenure}

Home ownership has been independently associated with improved health. It is thought that home ownership may generate a degree of security and control, though the direction of the relation needs further investigation. ${ }^{38}$ However, home ownership is not always health promoting. Nettleton and Burrows' study of the health impacts of mortgage arrears suggested that those living on the margins of home ownership suffer increased insecurity and detrimental mental health impacts. ${ }^{39}$ In addition, cultural variations in rates and meaning of home ownership may give rise to international variation.

\section{Housing design}

Flat dwelling has been linked to factors associated with stressful living conditions such as increased social isolation, crime, reduced privacy, and opportunities for safe play for children. ${ }^{40}$ However, there are many factors related to flat dwelling that may confound findings of surveys and there are no conclusive data that height of home from ground level is associated with reduced health or satisfaction with housing. ${ }^{41-43}$ A recent review ${ }^{44}$ of epidemiological surveys showed a consistent pattern of decreased levels of mental health associated with housing height and multiunit dwelling. It is unclear how these studies were selected for review and the authors point out that they are unable to draw conclusions of a causal link because of the poor quality of research in this area.

\section{OTHER CONSIDERATIONS IN HOUSING IMPROVEMENT PROGRAMMES}

In addition to factors associated with housing fabric and housing conditions there are some other associated factors that may be of relevance to a housing improvement programme.

\section{Moving and relocation}

Moving house is considered to be a stressful, health damaging life event. ${ }^{45}$ In the field of social housing this has been attributed to lack of opportunity to negotiate with the housing authority regarding control around the move. ${ }^{46}$ Housing relocation has also been associated with loss of community, uprooting of social networks, ${ }^{47}$ and unsatisfied social aspiration ${ }^{48}$ that may counteract satisfaction with improved housing. The meaning and context of housing varies between people and it may not be possible to detect tangible or consistent health effects of moving and relocation. ${ }^{49-51}$

Residents' satisfaction with their neighbourhood and dwellings has also been used as an indicator of quality of life and as an ad hoc measure of the success of housing investment. However, prioritising improvements in factors associated with high dissatisfaction may not maximise the incremental well being of residents; residents who are dissatisfied with the local neighbourhood may prioritise housing improvements before neighbourhood improvements. ${ }^{52}$ Consultation with residents included in proposed housing improvements is important.

\section{Displacement}

Some area and housing regeneration projects can lead to displacement of original residents. ${ }^{28}$ This may result in misleading shifts in routine social and health statistics that will not be identified unless a more detailed analysis of individual data is performed. It is therefore necessary to identify reasons and potential for displacement in advance.

\section{Area effects}

The socioeconomic characteristics of a neighbourhood may have an effect on a person's health status. ${ }^{53}$ Work ongoing in five large cities in the USA is looking at the health effects of relocation from areas of deprivation to improved housing in middle income areas. After 13 years employment opportunities, education, and social integration were improved. The suburban movers attributed increased employment to increased job vacancies, increased neighbourhood security, and less local gang activity. ${ }^{54}$ The most recent report from a similar project demonstrated that households in the intervention groups experienced improved health among household heads, and children in the experimental group were less likely than the control group children to experience an asthma attack. ${ }^{55 \mathrm{a}}$ 


\section{Key points}

- To improve the predictive value of health impact assessmen it is necessary to provide supporting research evidence.

- Using the example of housing, there is little research evidence of the health effects of improved housing; examination of a broader evidence base is required.

- Incorporating research evidence is only one part of HIA; balancing local knowledge and conflicting views is also required.

- Evaluation of the health impacts of future housing investment is required to inform HIAs of housing improvement and the development of healthy housing policy.

\section{Housing costs}

Research done in the USA supports the potential for rents to impact on residents' lives. In the USA housing or rent subsidies have been used as a way of offering public housing tenants more control and choice in where they live and of promoting more integrated public housing tenancy. This is done by means of housing vouchers that can be used in privately rented accommodation and allow low income families to consume more housing and free up funds to be spent on other work related expenses ${ }^{5657}$ as well as increasing employment opportunities and earnings. ${ }^{58}$ In one survey of child growth and nutrition, children whose family were on the waiting list for housing subsidy were over eight times more likely to have low growth indicators than similar children whose families already received a housing subsidy (OR $8.2,95 \%$ CI 2.2 to 30.4). ${ }^{59}$ However, voucher programmes are affected by and themselves affect other important and inter-related factors such as housing supply and demand levels ${ }^{60}$ and quality of new build subsidised housing. ${ }^{61}$

\section{USING EVIDENCE TO INFORM HEALTH IMPACT ASSESSMENTS OF HOUSING IMPROVEMENTS}

The purpose of health impact assessment of proposed housing interventions may be to recommend changes to maximise the health benefits arising, or to prioritise areas of housing investment. The summary of research evidence presented in this paper is a response to calls for usable evidence to inform future HIAs and policy decisions. By acting on these findings and considering both the potential positive and negative impacts of housing improvements, the health benefits of housing can be maximised.

In the current absence of intervention studies it is necessary to incorporate other sources of evidence. Data from qualitative studies can be used to identify possible mechanisms for unpredicted negative or positive impacts and inform adaptations to a proposed intervention. Longitudinal life course data can examine the long term health effects of exposure to poor housing. ${ }^{62}{ }^{63}$ Cross sectional epidemiological data can be used to inform and prioritise proposed interventions based on the strength of observed associations. Strength of observed associations can be ranked and applied to populations taking account of local population subgroups, for example, vulnerable groups. A locally responsive set of associated risks could then be used to prioritise vulnerable groups and the type of housing improvement. Risk estimates may also be used to predict and trade off the positive and negative impacts of the interventions between and within a population. However, it cannot be assumed that by reducing the exposure to a known housing risk the adverse effects of poor housing can be reversed. There are several well known examples of potentially effective interventions identified from observational research that fail to have the desired effect in practice ${ }^{64}{ }^{65}$ This means that although evidence of associated risk is important, it should be interpreted with caution as regards cause and effect.
Box 2 Evidence for health impacts after housing improvement derived from a systematic review of intervention studies

- Mental health likely to show some improvements.

- Possible small improvements in general physical health and wellbeing-though three studies of rehousing and regeneration showed adverse effects.

Box 3 Questions to ask in a housing HIA, informed by evidence from intervention studies, observational, and qualitative data reviewed

What are the specific housing changes/improvements that are proposed?

Are there other housing changes not detailed in the proposals that may occur?

What is the evidence that these changes will affect health and any specific symptoms?

Are there vulnerable groups (for example, elderly, asthmatic people) who may benefit particularly from the proposed changes?

When can health gains be realistically expected?

Will the improvement be too marginal to detect?

Are there going to be any changes in housing costs?

Is there any other change that may affect living coststransport, food, access to amenities?

Was there sufficient consultation about the housing improvements?

What is residents' baseline satisfaction level with their housing?

What levels of displacement can be predicted over the period of improvement?

What explanations might there be for displacement?

Incorporating best evidence into the process of HIA is essential but not straightforward. Locating and synthesising available research findings requires time and availability of specialised resources. In addition, there are problems with generalising research findings from one area to another. HIA has been described as "the use of the best available evidence to assess the likely impact of a specific policy in a specific situation ...the evidence must be weighed for its local relevance as well as its robustness" ${ }^{66}$ The review of research evidence provided here is only one aspect of an HIA and there will be many other aspects to consider. Consultation with experts and local stakeholders may predict additional, wider impacts, and may help explore the relative, local importance of predicted impacts. For example, the effects of the timescale of seeking funding to being rehoused, of accompanying regeneration rather than only rehousing, how other amenities may be affected. However, the views of stakeholders may conflict with the existing research findings. In these situations, decisions will need to be made on the balance of available evidence and local influences.

The difficulties in developing and using an evidence base for HIA has been recognised and a framework for different levels of HIA has been advocated. These levels range from a desktop exercise reliant on readily available information, to detailed assessment that included synthesis of existing research. ${ }^{267}$ Currently there is insufficient evidence to fully support a detailed HIA to predict the health impacts of housing improvement. The relative lack of evidence may seem to question the value of housing as a public health investment. However, it is important that absence of evidence is not confused with evidence of absence.

Validation of well designed HIAs has also been recommended. ${ }^{268}$ If this validation incorporated follow up after completion of the intervention to determine whether 
identified impacts actually took place it could contribute to the evaluation of housing improvements. Prospective validation of HIA predictions is now a priority. Well conducted validations will, hopefully be carried out and be able, in future, to inform the development of an evidence base for housing HIA and the development of healthy housing policy.

\section{ACKNOWLEDGEMENTS}

The authors would like to thank Marjorie Gaughan and David Morrison for their contribution to discussions in the Scottish Health Impact Assessment guideline development subgroup.

\section{Authors' affiliations}

H Thomson, M Petticrew, MRC Social and Public Health Sciences Unit, Glasgow, UK

M Douglas, Public Health, Lothian Health Board, Deaconess House, Edinburgh, UK

Funding: HT and MP are funded by the Chief Scientist Office of the Scottish Executive Department of Health. MD is funded by Lothian NHS Board. Mark Petticrew is a member of the ESRC Evidence Network.

Conflicts of interest: none.

\section{REFERENCES}

1 Acheson D. Independent inquiry into inequalities in health report. London: HMSO, 1998.

2 Parry J, Stevens A. Prospective health impact assessment: pitfalls, problems, and possible ways forward. BM 2001;323:1 177-82.

3 Mindell J, Hansell A, Morrison D, et al. What do we need for robust, quantitative health impact assessment? J Public Health Med 2001;23:173-8.

4 Thomson $\mathbf{H}$, Petticrew M, Morrison D. Health effects of housing improvement: systematic review of intervention studies. BM 2001;323:187-90.

5 Klinker S, Fitzpatrick S, Mitchell F, et al. A review of single homelessness: research summaries. Bristol: The Policy Press, 2000.

6 Klinker S, Fitzpatrick S. A bibliography of single homelessness research. Bristol: The Policy Press, 2000.

7 Effective Health Care Bulletin. Preventing falls and subsequent injury in older people. http://www0.york.ac.uk/inst/crd/ehc24pdf

8 Effective Health Care Bulletin. Preventing unintentional injuries in children and young adolescents. http://www2.york.ac.uk/inst/crd/ ehc25pdf

9 Hammarquist C, Burr M, Gotzsche P. House dust mite control measures for asthma. Cochrane Database of Systematic Reviews, 2000

10 DiGuiseppi C, Higgins J. Systematic review of controlled trials of interventions to promote smoke alarms. Arch Dis Child 2000;82:341-8.

11 Baba K, Baba M, Mizuno H, et al. Research into the achievement and impact of 'Assistance Programme for Healthy Housing' of Edogawa Ward. Annals of Japanese Public Health 1994;41:404-13.

12 Blackman T, Harvey J, Lawrence $M$, et al. Neighbourhood renewal and health: evidence from a local case study. Health \& Place 2001;7:93-104

13 Carp FM. Impact of improved housing on morale and life satisfaction. Gerontologist 1975;15:511-15

14 Carp FM. Impact of improved living environment on health and life expectancy. Gerontologist 1977;17:242-9.

15 Ambrose P. A drop in the ocean; the health gain from the Central Stepney SRB in the context of national health inequalities. London: The Health and Social Policy Research Centre, University of Brighton, 2000

16 Cole O, Farries JS. Rehousing on medical grounds: assessment of its effectiveness. Public Health 1986;100:229-35.

17 Green G, Ormandy D, Brazier J, et al. Tolerant building: the impact of energy efficiency measures on living conditions and health status. In: Nicol F, Rudge J, eds. Cutting the cost of cold. London: E \& FN Spon, 2000:87-103.

18 Hopton J, Hunt S. The health-effects of improvements to housing-a longitudinal-study. Housing Studies 1996;11:271-86.

19 Iversen M, Bach E, Lundqvist GR. Health and comfort changes among tenants after retrofitting of their housing. Environment International 1986;12:161-6.

20 Smith SJ, Alexander A, Easterlow D. Rehousing as a health intervention: miracle or mirage? Health \& Place 1997;3:203-16

21 Somerville M, Mackenzie I, Owen P, et al. Housing and health: does installing heating in their home improve the health of children with asthma? Public Health 2000;114:434-40.

22 Wilner DM, Price-Walkley R, Glasser MN, et al. The effects of housing quality on morbidity: preliminary findings of the Johns Hopkins longitudinal study. Am J Public Health 1958;48:1607-15.

23 Wilner DM, Price-Walkley R, Schram JM, et al. Housing as an environmental factor in mental health: the Johns Hopkins longitudinal study. Am J Public Health 1960;50:55-63.
24 Woodin S, Delves C, Wadhams C. 'Just what the doctor ordered': a study of housing, health and community safety in Holly Street, Hackney. Hackney, London: Comprehensive Estates Initiative, Hackney Housing Department, 1996.

25 Wambem DB, Piland NF. Effects of improved housing on health in South Dos Palos, Calif. Health Services Report 1973:88:47-58.

26 Green G, Gilbertson J. Housing, poverty and health: the impact of housing investment on the health and quality of life of low income residents. Open House International 1999;24:41-53.

27 McGonigle G, Kirby J. Poverty, nutrition and the public health. Poverty and public Health. London: Gillencz, 1936.

28 Walker R, Bradshaw N. The Oakdale renewal scheme: use of prescribing data to assess the impact on the health of residents. Cardiff: Gwent Health Authority \& Welsh School of Pharmacy, 1999.

29 Wells N. Housing quality and women's mental health: a 3 wave longitudinal study. Gavle, Sweden: European Network for Housing Research Conference: Housing in the 21 st century, 2000.

30 Halpern D. Improving mental health through the environment: a case study. In: Halpern D, ed. Mental health and the built environment: more than bricks and mortar? London: Taylor and Francis, 1995

31 Raw G. Building regulation health and safety. Watford, UK: Building Research Establishment, 2001.

32 Holmes P, Tuckett C, eds. Airborne particles: exposure in the home and health effects. Leicester: MRC Institute for Environment and Health, 2000.

33 Peat J, Dickerson J, Li J. Effects of damp and mould in the home on respiratory health: a review of the literature. Allergy 1998;53:120-8.

34 Curwen $M$. Excess winter mortality: a British phenomenon? Health Trends 1990/91;22:169-75.

35 Gemmell I, McLoone P, Boddy F, et al. Seasonal variation in mortality in Scotland. Int J Epidemiol 2000;29:274-9.

36 Gemmell I. Indoor heating, house conditions, and health. J Epidemiol Community Health 2001:55:928-9.

37 Wilkinson $\mathrm{P}$, Armstrong $\mathrm{B}$, Langon $\mathrm{M}$. The impact of housing conditions on excess winter deaths. York: Joseph Rowntree Foundation, 2001.

38 Hiscock R, Macintyre S, Kearns A, et al. Explanations for health inequalities between owners and social renters. Gavle, Sweden: European Network for Housing Research Conference: Housing in the 21 st century, 2000;

39 Nettleton S, Burrows R. Mortgage debt, insecure ownership and health: an exploratory analysis. Sociology of Health and IIIness 1998:20:731-53

40 Burridge R, Ormandy D. Unhealthy housing: research, remedies and reform. London: E \&FN Spon, 1993.

41 Marmot AF. Flats fit for families: an evaluation of post-occupancy evaluation. Design Studies 1983;4:92-9.

42 Hannay D. Mental health and high flats. Journal of Chronic Disease $1981 ; 34: 431-2$

43 Halpern D. The environment as a symbol. In: Mental health and the built environment. More than bricks and mortar? London: Taylor Francis, 1995: 149-233

44 Evans GW, Wells NM, Moch A. Housing and mental health: a review of the evidence and a methodological and conceptual critique. New York: Department of Agriculture, 2000: 1-26.

45 Hooper D, Ineichen B. Adjustment to moving: a follow-up study of the mental health of young families in new housing. Soc Sci Med 1979:13d:163-8.

46 Allen T. Housing renewal-Doesn't it make you sick? Housing 2000;15:443-61

47 Fried M. Grieving for a lost home. In: Wilson J, ed. Urban Renewal. Cambridge, MA: MIT Press, 1966.

48 Yuchtman-Ya'ar E, Spiro SE. Reactions to rehousing: loss of community or frustrated aspirations? Urban Studies 1979;16:113-19.

49 Danermark B, Ekstrom M. Relocation and health effects on the elderly a commented research review. Journal of Sociology and Social Welfare 1990;17:25-49

50 Ekstrom M. Elderly people's experiences of housing renewal and forces relocation: social theories and contextual analysis in explanations of emotional experiences. Housing Studies 1994;9:369-91.

51 Ekstrom M. Residential relocation, urban renewal and the well-being of elderly people. Comprehensive Summaries of Uppsala Dissertaions from the Faculty of Social Sciences. Uppsala: University of Uppsala, 1994:42.

52 Galster G. Evaluating indicators for housing policy: residential satisfaction vs marginal improvement priorities. Social Indicators Research 1985;16:415-48.

53 Pickett KE, Pearl M. Multi-level analyses of neighbourhood socioeconomic context and health outcomes: a systematic critical review. J Epidemiol Community Health 2001;55:111-22.

54 Rosenbaum J. Black pioneers- do their moves to the suburbs increase economic opportunity for mothers and children? Housing Policy Debate 1991:2:1179-213.

55 Rosenbaum J. Changing the geography of opportunity by expanding residential choice: lessons from the Gautreaux program. Housing Policy Debate 1995;6:231-69.

55a Katz LF, Kling JR, Liebman JB. Moving to opportunity in Boston: early results of a randomised mobility experiment. The Quarterly Journal of Economics 2001;116:607-54.

56 Olsen EO, Barton DM. The benefits and costs of public housing in New York City. Journal of Public Economics 1983;18:299-32.

57 Reeder WJ. The benefits and costs of the Section 8 existing housing program. Journal of Public Economics 1985;20:349-77.

58 Ong P. Subsidized housing and work among welfare recipients. Housing Policy Debate 1998;9:775-94. 
59 Meyers A, Frank D, Roos N et al. Housing subsidies and pediatric undernutrition. Arch Pediatr Adolesc Med 1995;149: 1079-84.

60 Apgar WC. Which housing oolicy is best? Housing Policy Debate 1990;1:1-32.

61 Kennedy S. Direct cash low-income housing assistance. In: Bloom H, Corday D, Light R, eds. Lessons from selected program and policy areas. San Francisco: Jossey-Bass, 1988.

62 Dedman D, Gunnell D, Davey Smith G, et al. Childhood housing conditions and later mortality in the Boyd Orr cohort. J Epidemiol Community Health 2001;55:10-15.

63 Marsh A, Gordon D, Pantazis, et al. Home sweet home? The impact of poor housing on health. Bristol: The Policy Press, 1999.
64 Omenn G, Goodman G, Thornquist $M$, et al. Effects of a combination of beta carotene and vitamin $A$ on lung cancer and cardiovascular disease. N Engl J Med 1996;334:1 150-5.

65 Macintyre S, Petticrew M. Good intentions and received wisdom are not enough. J Epidemiol Community Health 2000;54:802-3.

66 Scottish Needs Assessment Programme. Health Impact Assessment: piloting the process in Scotland. Glasgow: Scottish Needs Assessment Programme, 2000:22.

67 Scott-Samuel A, Birley M, Ardern K. The Merseyside guidelines for health impact assessment. Liverpool: Health Impact Assessment Steering Group, Liverpool Public Health Observatory, 1998.

68 Morrison D, Petticrew M Thomson $\mathrm{H}$. Health impact assessment and beyond. J Epidemiol Community Health 2001;55:219-20.

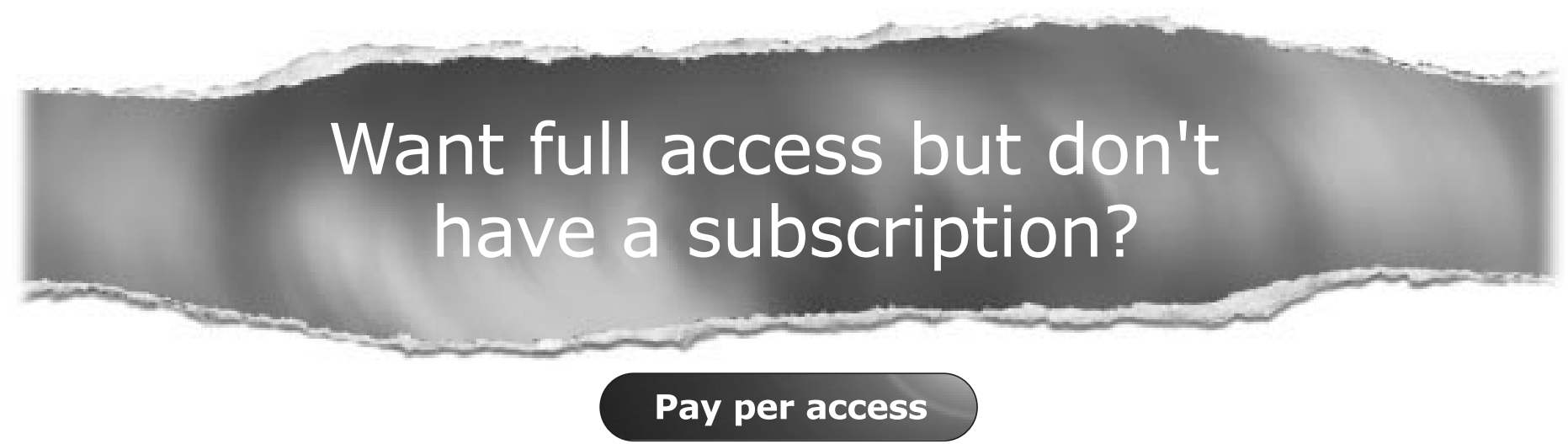

For just US $\$ 25$ you can have instant access to the whole website for 30 days. During this time you will be able to access the full text for all issues (including supplements) available. You will also be able to download and print any relevant pdf files for personal use, and take advantage of all the special features Journal of Epidemiology and Community Health online has to offer. 